\title{
"PARA QUE DELEITE A VISÃO E OS OLHOS" (TÁCITO, DIÁLOGO DOS ORADORES 22): ÉKPHRASIS OU DESCRIÇÃO NA HISTORIOGRAFIA TACITEANA
}

\author{
YGOR K. BELCHIOR* \\ Universidade Federal de Ouro Preto
}

\begin{abstract}
Resumo. Neste artigo temos como objetivo observar a ékphrasis na historiografia Taciteana a partir da hipótese de que a sua principal função era a de gerar o efeito de "visibilidade" e de "prova". Para tanto, focaremos no quadro metafórico da guerra civil empregado pelo historiador para descrever os conflitos entre a aristocracia e o imperador como "provas inartísticas" de que os eventos decorreram daquela maneira e ao mesmo tempo em que evidenciam o modelo histórico empregado por Tácito.
\end{abstract}

Palavras-chave. Tácito; Anais; Ékphrasis; Historiografia; Guerras Civis.

D.O.I. 10.11606/issn.2358-3150.v19i1p69-81

Quando representas como acontecendo no presente fatos ocorridos no passado, farás do discurso não mais uma narrativa, mas um drama real.

— Ps.-Longino, Do sublime, 25

DifERENTEMENTE DA PROPOSTA CIENTÍficA QUE PREDOMINOU DURANTE grande parte do século XIX, ${ }^{1}$ a historiografia antiga assumiu a relação entre as provas e as evidências documentais como compreendida no âmbito da afinidade entre a história e a retórica. No caso da última, é possível apontar que ela fornecia o material literário necessário ao orador para atingir a fides dos ouvintes (persuasão). ${ }^{2}$ Como o objetivo principal de uma obra do gênero historia também era a exposição verídica dos fatos, ${ }^{3}$ só que sem os

* Doutorando na Universidade de São Paulo. Integrante do Laboratório de Estudos sobre o Império Romano (LEIR/UFOP).

*Artigo recebido em 05.ago.2015 e aceito para publicação em 31.out.2015.

1 Tal visão positivista da História estava calcada em sua institucionalização como uma disciplina autônoma e que seria sobrecarregada pelos fardos da "verdade científica". Essa que era construída a partir da exposição científica da crítica interna e externa das provas documentais (evidência - evidence), cf. Belchior 2011a.

${ }^{2}$ A exemplo da Retórica de Aristóteles.

${ }^{3}$ No caso de Tácito, sua proposta era a de fazer uma história sine ira et studio ("sem ira nem afeição", Tac., Anais. 1, 1, 4). 
nossos modernos recursos de citação de uma documentação, era necessário ao historiador antigo encontrar outras maneiras para expor as evidências (provas) que embasaram a sua argumentação.

Neste texto, abordaremos dois instrumentos literários que foram utilizados pelo historiador latino de nome Públio Cornélio Tácito (séculos I e II d.C.) visando criar o "efeito de verdade" a respeito da sua versão sobre o passado. ${ }^{4}$ A saber, falamos aqui da fabricação da evidência (euidentia), o equivalente latino para enárgeia, ${ }^{5}$ e da ékphrasis, que tinha a função de colocar diante dos olhos dos ouvintes as palavras que proferidas pelo orador. ${ }^{6}$ Nosso objetivo, portanto, é o de observar como tais ferramentas agiam em uma dupla condição: como o objetivo das narrativas historiográficas e como geradora da enárgeia, ou seja, do "efeito de verdade" e a exposição da "evidência" histórica.

\section{HISTÓRIA VS. RETÓRICA}

Neste ponto, partimos das mudanças dentro da compreensão epistemológica sobre a prática historiográfica e que fomentaram os debates acadêmicos ao longo do último século xx. Influenciados pelas ideias de Woodman, ${ }^{7}$ tais produções se incumbiram de construir a compreensão de que a historiografia antiga era apenas um constructo literário e que não tinha nenhum compromisso com a exposição empírica dos fatos passados. ${ }^{8}$ A culpa disso recaiu no uso da retórica, entendida por eles como um instrumento para o "falseamento" das narrativas.

De tal forma, a historia, como um gênero literário, passou a ser confundida com as práticas poéticas antigas, como a épica. Isto é, vista em termos de fabula/psêudo/fictio, sem nenhum compromisso com a "verdade histórica". Em vista disso, o único objetivo traçado para essas produções estaria centrado em um convencimento a todo custo dos ouvintes - tratados como juízes

\footnotetext{
${ }^{4}$ Sobre a biografia de Tácito Cf. Belchior 2011b, 4-5.

${ }^{5}$ Quint., Inst. 4.6.63.

${ }^{6}$ Her., 4.59.

${ }^{7}$ Woodman 2009.

${ }^{8}$ A exemplo do trabalho de Nobre 2010.

${ }^{9}$ Apesar dessa concepção apresentada, não devemos deixar de destacar que, para os antigos, tal fato não significava que os dois gêneros pudessem ser identificados como similares. Afinal, eles possuíam as suas próprias regras e divisões internas específicas. Como exemplo, basta atentarmos para os diferentes tipos de poesia apontados por Aristóteles ( $P$ o. 1447a) e os diferentes tipos de história indicados por Políbio (Hist. 9,1).
} 
- que deveriam ser educados (docere), movidos à ação (moure) e deleitados (delectare) por elementos de cunho literário estritamente persuasivos. ${ }^{10}$

Na obra Diálogo dos Oradores, atribuída a Tácito, ${ }^{11}$ é possível encontrar referências que confirmam as ideias de Woodman. Nesta obra, o auctor, na voz de Marcos Apro, defende uma oratória mais próxima das práticas poéticas. Em uma passagem específica, por exemplo, o narrador destaca que os juízes ou os ouvintes estavam cansados da dureza e da lucidez dos oradores austeros. ${ }^{12}$ Os mesmos que sempre produziram discursos que não eram dignos de memória.

A solução apresentada por Apro, de tal forma, perpassava a compreensão de que aquilo que poderia vir a tornar uma narrativa "digna de memória", ou a chamar a atenção do ouvinte, seria uma abordagem estritamente literária que colocaria as "palavras diante de seus olhos". ${ }^{13}$ Para atingir isso, o orador deveria se servir do colorido, da animação e da beleza de outros discursos, que não soariam, assim, "manchados pelas velharias de Ácio ou de Pacúvio". ${ }^{14}$ Mas chegariam "aos ouvidos dos juízes com certo apaziguamento". ${ }^{15}$

Outro exemplo importante pode ser extraído do capítulo 22. Nele, o auctor referência ao gênero Anais como composto por frases de "tardia e deselegante estrutura", completamente desvinculado da "vividez" que era proporcionada pelas ornamentações e licenças poéticas. A culpa disso, segundo Tácito, recairia nos ouvidos exigentes da plateia que ansiavam por composições que fossem retiradas "do santuário de Horácio, de Virgílio e de Lucano". Assim, era necessário aos oradores de seu tempo que dialogassem com os poetas, no intuito de que seus discursos pudessem ser mais "visíveis" e, portanto, que dignos dos ouvidos atendo da audiência.

Como sabemos, Tácito compôs uns Anais que são intitulados dessa forma. A obra em questão tem os seus livros divididos em capítulos que são demarcados pelos anos em que governaram os cônsules romanos, principal característica de tal gênero. ${ }^{16}$ Dentro da lógica descrita no parágrafo anterior, não devemos deixar de atentar para a ideia de que na leitura dos Anais,

${ }^{10}$ Woodman 2004a.

${ }^{11}$ Esta obra foi atribuída a Tácito devido à descoberta de um códice no monastério de Hersfeld, na Alemanha, no século xv. Nesse códice, estavam compiladas as chamadas obras menores (Germânia, Vida de Agrícola e Diálogo dos Oradores). Cf. Joly 2004.

12 Tac., Dial. 20.

${ }_{13}$ Tac., Dial. 22.

14 Tac., Dial. 20.

${ }_{15}$ Tac., Dial. 20.

${ }^{16}$ Além disso, podemos encontrar referências em passagens extraídas dos Anais que confirmem referências ao gênero discursivo proposto pelo historiador latino: Tac., Ann. 2.65; 4.32.1; 13.31.1. 
de Tácito, podemos perceber uma amplificação do próprio gênero discursivo feito de maneira literária. Ou seja, em uma obra que a princípio deveria ser enxuta (somente os principais acontecimentos dos cônsules) e estritamente cronológica, o que podemos observar são características do gênero historiográfico e do gênero poético que auxiliam no deleite dos ouvintes e na criação do "efeito de verdade".

Esses exemplos nos oferecem os fundamentos necessários para direcionarmos a nossa reflexão para a tentativa de compreensão das figuras retóricas que eram utilizadas por Tácito para que o seu discurso pudesse ser tomado como verossímil. Nossa proposta na continuação deste estudo, portanto, é atentar para o estudo da obra Anais de Tácito, tendo em vista a proposta anteriormente citada, onde a ékphrasis nos é apresentada como o objetivo das narrativas historiográficas e como geradora da enargeia.

\section{TÁCITO E SUAS HISTÓRIAS}

Antes de prosseguirmos nossa linha de raciocínio, uma pausa para apresentarmos as obras analisadas neste trabalho se faz necessária. Sobre elas, podemos afirmar que Tácito possui uma significativa produção intelectual em diversos gêneros que foi preservada. A exemplo, podemos nos referir a obra de cunho étnico intitulada Germânia, o tratado oratório Diálogo dos Oradores e a biografia de Agrícola. Além delas, temos duas obras historiográficas, que serão o foco deste trabalho: os Anais e as Histórias. ${ }^{17}$

Sobre a história desse material, os Anais e as Histórias chegaram até nós graças a dois códices: Mediceus prior e Mediceus alter. O primeiro é datado da segunda metade do século IX d.C. e o segundo de meados do século xI d.C. O Mediceus alter contém os seis últimos livros que conhecemos dos Anais (11-16) e imediatamente depois, com a numeração sequenciada e sem título, os quatros primeiros livros completos das Histórias, somado a um breve fragmento do quinto (17-21); Já, o Mediceus prior, sob o título de $A b$ excessu diui Augusti libri, contém os quatro primeiros livros dos Anais, os cinco primeiros capítulos do livro 5 (o quinto capítulo está pela metade) e a parte final do livro $6 .^{18}$

${ }^{17}$ Para uma descrição ampliada das obras de Tácito, cf. Belchior 2016.

${ }_{18}$ O Mediceus prior no século XVIII passou a formar parte da Biblioteca Laurenziana de Florença, sob o registro LXVIII, 1. Esse manuscrito foi encontrado na abadia de Korvey, em Westfalia, nos finais do século XV. Dali foi transferido para a Itália e, em 1509, passou para as mãos do cardeal Juan de Medicis que, ao assumir o pontificado sob o nome de Leão X, encarregou o humanista Filippo Beroaldo de sua impressão. Ela foi concluída no ano de 1515. O Mediceus alter foi copiado 
As noções dominantes sobre a organização desse material foram sustentadas por pesquisadores como Woodman e Zuñiga, ${ }^{19}$ e desenvolvidas sob a noção de que as Histórias e os Anais corresponderiam a uma contagem sequencial de trinta livros de uma obra monumental. A lógica seria a seguinte: os Anais compondo os dezesseis primeiros livros e as Histórias, obviamente, os catorze últimos. ${ }^{20}$ Nesse sentido, o objetivo principal de Tácito ficou claro para esses autores. Sua ideia capital, portanto, era a de fazer uma historia que começaria com a morte do divino Augusto, terminando na narrativa do governo de Trajano. O motivo disso estaria na centralidade de seu objeto, que era a instituição da tirania dos príncipes e no regime de sucessão dinástico (o que explicaria seu começo com Tibério).

Todavia, mesmo com essas interpretações dominantes sobre o material em uma ordem cronológica dos acontecimentos, é possível encontrar outra leitura. De tal forma, o que também podemos constatar a partir da datação de seus escritos é que o Tácito se propõe, primeiramente, a compor as suas Histórias, cuja narrativa se inicia no ano de 69. É somente depois dessa obra que ele se debruça na tentativa de escrever outra (os Anais), na qual narra acontecimentos de um passado anterior. Em outras palavras, ao que parece, para o historiador latino, a sequência cronológica dos acontecimentos não era tão importante assim.

Sob tal foco, atentamos aqui que as obras analisadas podem ser lidas como tendo seus recortes cronológicos nos acontecimentos que estão compreendidos em dois períodos de guerras civis: a vitória de Augusto e o ano dos quatro imperadores. Uma visão contrária àquela apresentada por Woodman e Zuñiga e que foca nos governos dos imperadores. Tal fato fica ainda mais evidente quando historiador latino afirma que os anos anteriores aos das guerras civis de 69 são essenciais para explicar as suas causas. Citamos a obra:

Ceterum antequam destinata componam, repetendum videtur qualis status urbis, quae mens exercituum, quis habitus provinciarum, quid in toto terrarum orbe validum, quid aegrum fuerit, ut non modo casus eventusque rerum, qui plerumque fortuiti sunt, sed ratio etiam causaeque noscantur. ${ }^{21}$

em letra lombarda, em meados do século xI, na abadia de monte Casino. No ano de 1370, foi descoberto por Boccaccio que o transferiu para Roma. Posteriormente, esse manuscrito passou para o convento de São Marcos, em Florença, para a Biblioteca Laurenziana, sob o registro LXVIII, 2. Cf. Zúñiga 2002, xviII.

${ }^{19}$ Woodman 2004b; Zúñiga 2002, 9-34.

${ }^{20}$ Conforme apontado por ambos os autores, a nomenclatura do primeiro livro das Histórias, intitulado Cornelii Taciti liber XVII, na organização que foi encontrada nos códices também confirma tal afirmação sobre a organização do corpus documental de Tácito.

${ }^{21}$ Tac., Hist 1.4. 
Acredito que seja mais apropriado, no entanto, antes de iniciar o trabalho que foi proposto, revisar as condições da cidade de Roma, o temperamento dos exércitos, a atitude das províncias e os elementos de fraqueza e de força que existiam em todo o império, de forma que possamos conhecer, não somente as vicissitudes ou os discursos construídos sobre os eventos, que muitas vezes são questões de fortuna, mas também as suas relações e as suas causas. ${ }^{22}$

Essa manobra realizada por Tácito no proêmio de suas Histórias pode ser interpretada como uma relação de "causa e efeito" (sed ratio etiam causaeque noscantur). Ou seja, podemos afirmar que o historiador faz aqui uma "arqueologia" do passado para explicar porque os romanos enfrentaram "aquele único e longo ano de Galba, Oto e Vitélio". ${ }^{23}$ Para tal intuito, afirma que irá retroceder ao estado da urbs e atentar para as questões condizentes com o temperamento dos exércitos, a atitude das províncias e e os elementos de fraqueza e de força que existiam ao longo do império. ${ }^{24} \mathrm{Em}$ vista disso, partiremos do princípio que as guerras civis do ano de 69 d.C. possuem grande influência nas obras históricas de Tácito. ${ }^{25}$

\section{HISTÓRIA, RETÓRICA E GUERRAS CIVIS}

Já apontamos as principais diferenças entre os estudos fomentados por White e por Woodman no campo da historiografia antiga em relação àquela que fora praticada pelos teóricos positivistas do século XIX. Sobre as contribuições mais importantes desse debate, podemos ressaltar novamente que elas residem no resgate do estudo das antigas noções da historia como um gênero literário. Portanto, calcada em preceitos retóricos e oratórios. Cabe destacar que durante muitas décadas tal visão foi a que predominou nas leituras realizadas das obras históricas de Tácito. ${ }^{26}$

${ }^{22}$ Tradução do inglês: "I think it proper, however, before I commence my purposed work, to pass under review the condition of the capital, the temper of the armies, the attitude of the provinces, and the elements of weakness and strength which existed throughout the whole empire, that so we may become acquainted, not only with the vicissitudes and the issues of events, which are often matters of chance, but also with their relations and their causes". Cf. Wellesley 1995.

${ }^{23}$ Tac., Dial., 17.

${ }^{24}$ Essa mesma perspectiva é compartilhada por Sailor 2008 e Syme 1957 e 1967.

${ }^{25}$ Como sabemos, foi após a morte do imperador Nero que a guerra civil se instaura novamente. Esse fato é fortemente marcado pela famosa sentença, proferida por Tácito, de que "o segredo do império havia sido descoberto, e que um imperador poderia ser feito fora de Roma" (Tac., Hist. 1, 4) - evulgato imperii arcano posse principem alibi quam Romae fieri.

${ }^{26}$ Haynes 2003, O’Gorman 2000. 
Como exemplo dessa influência, Nobre, em seu livro Intrigas palacianas nos Annales de Tácito: tentativas e processos de obtenção de poder no principado de Tibério, se debruça na empreitada de estudar os Anais a partir da noção desenvolvida por esses autores. Pensando a historia dessa maneira, o autor aponta que Tácito estaria interessado na guerra apenas para criar um clima de tensão calcado na ideia de que a guerra civil vencida por Augusto ainda não havia terminado. Dessa forma, apoiando-se em suas habilidades retóricas e dramáticas, o historiador descreveu os anos da dinastia JúlioCláudia com o uso descriminado de estruturas dramáticas e poéticas, sem a preocupação de que os eventos relatados poderiam ter alguma conexão com a "realidade histórica". ${ }^{27}$

Todavia, apesar do predomínio desse tipo específico de leitura, nosso trabalho recairá naquilo que realmente se esperava de um historiador antigo: o relato de uma realidade passada e feito de uma forma verossímil. Isso não significa refutar tudo aquilo que foi dito anteriormente. Pelo contrário, nosso objetivo nesta parte será o de realizar uma releitura das obras antigas com o intuito de entender como a abordagem literária não se afastava de uma abordagem puramente histórica - e até certo ponto empírica. Em nossa proposta, portanto, as guerras civis terão muito mais o papel de evidenciar e de dar uma dinâmica aos acontecimentos do que aquela focada no deleite de uma plateia ávida por uma boa composição fictícia.

Começamos pelo resgate da retórica antiga feito pelos autores citados. Como vimos, tanto Nobre, como White e Woodman concordam que a retórica servia como uma ferramenta de "falseamento" e de "ornamento", marcada pelo convencimento a todo custo. Essa preocupação é demonstrada pelo tradutor da Retórica de Aristóteles para o português:

Para muitos, a retórica pouco mais é do que mera manipulação linguística, ornato estilístico e discurso que se serve de artifícios irracionais e psicológicos, mais propícios à verbalização de discursos vazios de conteúdo do que à sustentada argumentação de princípios e valores que se nutrem de um raciocínio crítico válido e eficaz. ${ }^{28}$

Note-se que na obra referida o tradutor busca se afastar da ideia até então defendida para o entendimento da retórica clássica. Outro pesquisador que demonstrou tal preocupação foi Ginzburg. Em sua introdução a obra Relações de força: História, Retórica e Prova, o autor buscou definir em linhas gerais a ideia de que os historiadores antigos possuíam outra forma de proceder em relação ao que atualmente entendemos como retórica. Uma

\footnotetext{
${ }_{27}$ Nobre 2010.

${ }^{28}$ Júnior 2005, 9.
} 
dessas formas, consiste em estudá-la em um viés muito mais amplo, ou seja, a partir da concepção de que a prova discursiva era considerada como parte integrante do sistema retórico. ${ }^{29}$ É preciso, portanto, olhar como os antigos concebiam essa ciência e não a sua interpretação moderna.

Conforme apresentado por Quintiliano, ${ }^{30}$ a retórica possuía quatro definições básicas na antiguidade: geradora de persuasão (Córax, Tísias, Górgias e Platão); a capacidade de descobrir os meios de persuasão relativos a um dado assunto (Aristóteles); a faculdade de falar bem no que concerne aos assuntos públicos (atribuída a Hermágoras); e a noção atribuída ao próprio Quintiliano, da retórica como scientia bene dicendi (a ciência de bem falar). ${ }^{31}$ Dentre elas, cabe destacar que a noção dominante era a de Aristóteles.

Destarte, para o filósofo grego, a retórica é essencialmente uma retórica da prova, do silogismo retórico; ou seja, uma teoria da argumentação persuasiva. ${ }^{32}$ Como uma "capacidade de descobrir o que é adequado a cada caso $^{\prime \prime},{ }^{33}$ Aristóteles nos apresenta as provas e as técnicas de persuasão que o orador deveria escolher para compor um discurso que visasse atingir a pístis (equivalente grego de fides) de seus ouvintes.

Sobre as provas de persuasão, o filósofo as classifica em dois tipos: 1 . As inartísticas, isto é, todas as que não são produzidas pelo orador, como testemunhos, confissões sob tortura, documentos escritos e outras semelhantes; 2. E as artísticas, ou todas as que podem ser preparadas pelo método retórico ou pelo próprio orador. ${ }^{34} \mathrm{Em}$ uma aplicação mais prática, o orador segundo Aristóteles deveria compor o discurso utilizando as primeiras provas (inartísticas) e inventando as segundas (artísticas).

Cabe ressaltar ainda que cada meio de persuasão deve ser condizente com o subgênero da retórica que o orador se propõe a pronunciar em uma elocução. Pois, como indica Aristóteles, as espécies de retórica devem ter como fim as diferentes audiências em diferentes situações. ${ }^{35}$ Dentro da perspectiva aristotélica, portanto, são apresentados três tipos de gêneros retóricos: o deliberativo, o epidíctico e o judiciário. ${ }^{36}$

Em linhas gerais, o deliberativo consiste nas coisas que afetam o ouvinte pessoalmente. Como as finanças, guerra e paz, defesa nacional, im-

${ }^{29}$ Ginzburg 2002, 13

${ }^{30}$ Quint., Inst. 2.15.1-38.

${ }^{31}$ Também podemos incluir nessa lista a definição expressa pelo auctor de Retórica a Herênio

(1.1), onde aparece como ratione dicendi (arte do falar) e rationem dicendi (ciência do discurso).

${ }^{32}$ Arist., Rh. 1354a.

${ }^{33}$ Arist., Rh. 1355b.

${ }^{34}$ Arist., Rh. $1355 b$.

${ }^{35}$ Arist., Rh. $1358 \mathrm{~b}$.

${ }^{36}$ Essa mesma tripartição aparece em Her., 1.2. 
portações, exportações e legislação. ${ }^{37}$ A sua argumentação consiste naquilo que é bom ou ruim para os cidadãos, pois seu ambiente é a assembleia. Já, o tempo que lhe é apropriado consiste nas deliberações para o futuro da comunidade, ${ }^{38}$ e seu objetivo é aconselhar ou dissuadir a respeito dos assuntos que poderão acontecer. O seu fim é a felicidade. ${ }^{39}$

Sobre o gênero epidíctico (ou demonstrativo), ele trata do encômio e do vitupério (elogio e censura), com o intuito de incitar seus ouvintes à ação. Apesar de se servir do passado como fonte de exemplos, é a respeito do presente e do futuro que o objetivo do epidídico está focado. Para atingir tal finalidade, nesse gênero é permitido o uso de amplificações (tais como na poesia) para que o elogiado, assim como um fato histórico, se torne exemplo. Também é no campo do epidíctico que são mais apropriados a elaboração de discursos escritos, pois a sua função é de ser lido.

Quanto ao judiciário, suas matérias são a acusação e a defesa no âmbito dos processos judiciais. Seu lugar é o fórum e seu tempo de atuação é o passado, pois trata de coisas que já aconteceram e que serão julgadas. Esse tipo de discurso possui como finalidade o convencimento dos juízes. Para tanto, cabe ao orador, ou no caso um advogado, mostrar-se mais rigoroso nos pormenores de sua exposição e das provas para que também possa predispor o auditório a apoiar o seu argumento. ${ }^{40}$

Apesar de comumente associado ao epidíctico por ser um discurso escrito, o gênero historiográfico na antiguidade possui elementos que competem aos três subgêneros retóricos descritos anteriormente. ${ }^{41}$ Sobre o orador do epidíctico, ou o historiador, Aristóteles assume que ele não possui responsabilidade sobre os fatos narrados e deve apenas demonstrar como determinada ação se realizou. Isso porque todos os assuntos narrados são do conhecimento da audiência..$^{42}$ Logo, cabe ao orador realizar a amplificação dos fatos e o elogio ou o vitupério das ações dos indivíduos. Realizando, portanto, os mesmos processos de construção e levantamento de provas inartísticas e artísticas para tal intento.

Uma vez que toda a matéria concernente à retórica estava relacionada com a opinião pública, cabia, deste modo, aos oradores realizar o exercício de composição de seus discursos dentro dos moldes do próprio sistema retórico. Pois o mesmo valia para aqueles que iriam avaliar o assunto

\footnotetext{
${ }^{37}$ Arist., Rh. 1359b.

${ }^{38}$ Arist., Rh. 1364a.

${ }^{39}$ Arist., Rh. 1360b.

${ }^{40}$ Arist., Rh. 1414a.

${ }^{41}$ Arist., Rh. 1414a.

${ }^{42}$ Arist., Rh. 1415a.
} 
proferido. ${ }^{43}$ Dessa maneira, podemos entender que esse sistema aristotélico funcionava em três vias: na composição do discurso, na sua elocução e na recepção pelo ouvinte.

Um dos procedimentos empregados pelos discursos antigos é o da enargéia ou evidência. O equivalente latino da enargéia é o ornamento de sentença demonstratio, ou seja, a capacidade de exprimir (seja literal ou oralmente) "um acontecimento com palavras tais que as ações parecem estar transcorrendo e as coisas parecem saltar diante dos olhos". ${ }^{44}$ Assim, o orador se apropriava de figuras e ornamentos que davam vida ao seu discurso como uma forma de gravar na memória da audiência os exemplos que desejava demonstrar.

Outro procedimento aplicado era o da ékphrasis ou descrição. Tal como a enargéia, ela tinha a função de colocar diante dos olhos, gerando um efeito de "visibilidade" de qualquer objeto (inanimado ou não) descrito. Um dos procedimentos da ékphrasis é a descrição de pessoas. Essa prática é muito importante para o discurso epidíctico, tendo em vista que auxilia na descrição do êthos dos personagens encomiados ou vituperados. Tais comportamentos eram essenciais para o critério de avaliação por parte do público do caráter de uma determinada autoridade, já que essa associação é feita geralmente calcada pela descrição das pessoas que os cercavam.

Em Tácito, também podemos observar a forte presença da construção de um conjunto de comportamentos que são atribuídos aos personagens de sua narrativa. Segundo Azevedo, esse comportamento artístico por parte do historiador deve ser entendido como a tentativa de construção de retractos. ${ }^{45}$ Com isso, temos a produção de uma evidentia in narratione que estaria, de tal forma, muito próxima a concepção de historia magistra vitae fornecedora de exemplos. ${ }^{46}$

De forma similar, podemos expandir esse raciocínio e atribuir a construção de retractos também a situações "metafóricas" que englobavam características de determinados quadros temporais. No caso da guerra civil, temos aqui um gancho para começar a vê-la como uma evidência his-

${ }^{43}$ Arist., Rh. 1404a.

${ }^{44}$ Her., 4.68. Essa mesma aplicação da evidentia como exposição da matéria tratada com muita clareza também é defendida por Quint., Inst. 8.3.61-5.

45 "Palavra que deriva de retraho, "retirar", pois o autor "retira" os argumentos, se baseando em características de pessoas ou acontecimentos e que lhe são úteis para a construção da representação da personagem ou situação". Cf. Azevedo 2011.

${ }^{46}$ Como exemplo, podemos ler a passagem em que Tácito descreve a designação do general Corbulão para o comando do conflito na região da Armênia como uma contraposição as virtudes, tanto do jovem imperador Nero, como também aos outros aristocratas que não ascendiam às maiores magistraturas através de seus méritos. Sobre essa relação entre o comandante e o imperador temos a monografia de bacharelado de Mariana Alves de Aguiar. Cf. Aguiar 2010. 
tórica e não mais como um ornamento. Como exemplo dessa afirmação, é muito sintomática a seguinte descrição de acontecimentos do governo de Tibério. Em suas palavras:

instabat quippe Seianus incusabatque diductam civitatem ut civili bello: esse qui se partium Agrippinae vocent, ac ni resistatur, fore pluris; neque aliud gliscentis discordiae remedium quam si unus alterve maxime prompti subverterentur.

A isso dava todo motivo Sejano, que lhe afirmava estar já Roma dividida em partidos como nos tempos das guerras civis; e que mesmo havia já indivíduos que se intitulavam do partido de Agripina: e que se não se desse logo um pronto remédio, podia muito bem ter consequências funestas. Que não havia pois outro meio para abafar na sua origem estas discórdias senão castigar fortemente um outro chefe dos mais atrevidos (Tac. Ann. 4.17.3). ${ }^{47}$

Esse clima de tensão aparece em diversas passagens dos Anais e demonstra como os retractos dos traumáticos conflitos podem servir como "efeito de visibilidade" e como evidência. Isto é, falamos da utilização de uma ékphrasis ou descrição para gerar a enargeia. Visto isso, recorremos novamente às ideias de Aristóteles para entendermos a íntima relação entre o efeito de visibilidade do discurso e a criação de um "efeito de verdade". Em suas palavras:

Se o temor é isto, forçoso é admitir que as coisas temíveis são as que parecem ter um enorme poder de destruir ou de provocar danos que levem a grandes tristezas. É por isso que os sinais dessas eventualidades inspiram medo, pois mostram que o que tememos está próximo. O perigo consiste nisso mesmo: na proximidade do que é temível (Arist., Rh. 1382a). ${ }^{48}$

\section{Assim,}

Quando for vantajoso para um orador que os ouvintes sintam temor, convém adverti-los no sentido de que pode acontecer-lhes mesmo alguma coisa de mal (sabendo que até outros mais poderosos que eles também sofreram); convém ainda demonstrar-lhes como é que gente da mesma condição sofre ou já sofreu, tanto por parte de pessoas de quem não se esperaria, como por coisas e em circunstâncias de que não se estava à espera (Arist. $R h$ 1383a). ${ }^{49}$

Em suma, a partir dessa leitura da historiografia focada nas técnicas de produção de evidências discursivas nos auxilia a compreender a maneira pela qual o orador se apropria do artístico para criar uma sensação

\footnotetext{
${ }^{47}$ Tradução de José Liberato Freire de Carvalho. Cf. Tácito 1952. [Grifo nosso].

${ }^{48}$ Tradução de Manuel Alexandre Junior, Paulo Farmhouse Alberto e Abel do Nascimento Pena.

${ }^{49}$ Idem.
} 
de "visibilidade" dos acontecimentos e das ações relatadas. Essa escolha empreendia muito mais que o deleite, pois, como vimos, a história possuía também a função de instruir através de exemplos (caráter pedagógico) que todos as pessoas já conheciam. Era preciso, deste modo, ao historiador encontrar uma maneira "artística" e literária para evidenciar algo empírico, como prova de que aquilo se passou daquela maneira.

\section{CONCLUSÃO}

Para um historiador interessado em explicar os acontecimentos do ano de 69 d.C., a aplicação das guerras civis para descrever os conflitos entre a elite senatorial e o imperador, portanto, é condizente com as técnicas retóricas da ékphrasis/descrição e não afasta o historiador do seu objetivo da "verdade". Essa observação basta para entendermos a ékphrasis no exercício da historiografia com a principal função de gerar o efeito de "visibilidade" e de "prova". Sendo assim, o quadro metafórico da guerra, marcado por "ordens cruéis, acusações contínuas, amizades enganosas, ruína inocentes" (Tac., Ann., 4, 33, 3), , $^{0}$ temas recorrentes em Tácito, funcionam como "provas inartísticas" e ao mesmo tempo para evidenciar o seu modelo histórico.

\section{REFERÊNCIAS}

Aguiar. 2010. O General e o Imperador: Relações de poder na luta pela conquista da Armênia. Graduação em História. Mariana: UFOP.

Azevedo. 2011. Consilium muliere ac deterius (Tac., Ann. 15, 54, 5): Interações sociais, personagens femininas e construção da imagem imperial no principado de Nero. Dissertação de Mestrado em História. Mariana: UFOP.

Belchior, Ygor K. 2011a. "A história como um romance? Uma discussão da contribuição teórica da vertente pós-modernista para os estudos sobre a historiografia Taciteana". Revista Ágora 7:1-22. Vitória.

Belchior, Ygor K. 2011b. “Biografia de Públio Cornélio Tácito [Publius Cornelius Tacitus]." Philía 4-5. Rio de Janeiro.

Belchior, Ygor K. 2016. Nero: bom ou mau imperador? Retórica, política e sociedade em Tácito (54 a 69 d.C). Curitiba: Prismas.

50 "nos saeva iussa, continuas accusationes, fallaces amicitias, perniciem innocentium et easdem exitii causas coniungimus, obvia rerum similitudine et satietate"; tradução de Fábio Duarte Joly. Cf. Joly 2001. 
Ginzburg. 2002. Relações de força: História, Retórica e Prova. Tradução de Jônatas Batista Neto. São Paulo: Companhia das Letras.

Haynes. 2003. The History of Make-Believe: Tacitus on Imperial Rome. Berkeley and Los Angeles: University of California Press.

Joly, Fábio D. 2001. “Teleologia e Metodologia Históricas em Tácito." História Revista 6(2):25-50. Goiânia.

Joly, Fábio D. 2004. Tácito e a metáfora da escravidão. São Paulo: Edusp.

Junior, Manuel Alexandre. 2005. "Introdução". In Aristóteles, Retórica. Tradução de Manuel Alexandre Junior, Paulo Farmhouse Alberto e Abel do Nascimento Pena. Lisboa: Biblioteca de Autores Clássicos.

Nobre. 2010. Intrigas palacianas nos Annales de Tácito: tentativas e processos de obtenção de poder no principado de Tibério. Coimbra: Centro de Estudos Clássicos e Humanísticos.

O'Gorman. 2000. Irony and misreading in the Annals of Tacitus. Cambridge: Cambridge University Press.

Sailor. 2008. Writing and empire in Tacitus. Cambridge: Cambridge University Press.

Syme. 1957. "How Tacitus Came to History". G\&R 4(2):160-7.

Syme. 1967. Tacitus. London: Oxford University Press.

Tácito. 1952. Anais. Trad. J. L. Freire de Carvalho. São Paulo: W. M. Jackson Inc. Editores. (Clássicos Jackson, XXV).

Wellesley, Kenneth. 1995. "Introduction." In Tacitus. The Histories. Translated by Kenneth Wellesley. London: Penguin.

Woodman, A. J. 2004a. "History and Alternative Histories: Tacitus." In Rhetoric in Classical Historiography: four studies, 160-96. New York: Routledge.

Woodman, A. J. 2004b. "Introduction". In Tacitus, The Annals. Translated by A.J. Woodman. Indianapolis/Cambridge: Hackett Publishing Company.

Woodman, A. J. 2009. "Tacitus and the contemporary scene." In The Cambridge Companion to Tacitus, edited by J. Woodman, 31-46. New York: Cambridge University Press.

Zúñiga, José Tapia. 2002. "Prólogo". In Anales, de Cayo Cornelio Tácito. Trad. José Tapia Zúñiga. México: Universidad Nacional Autónoma de México. (Bibliotheca Scriptorvm Graecorvm et Romanorvm mexicana).

\section{*}

Title. Ékphrasis in Tacitus' historiography.

Abstract. In this article, we aim to observe the ékphrasis in Tacitus' historiography from the hypothesis that its main function was to create the effect of "visibility" and "evidence". Therefore, we will focus on the metaphorical framework of the civil wars which is employed by the historian to describe the conflicts between the aristocracy and the emperor as an "inartistic evidence" that the events took place in that way, and at the same time they reveal the historical model employed by Tacitus.

Keywords. Tacitus; Annals; Ékphrasis; Historiography; Civil Wars. 